\title{
Morfofisiologia do tecido intertubular e das células de Leydig de jaguatirica (Leopardus pardalis) adulta
}

\author{
[Morphophisiology of the intertubular tissue and Leydig cells in adult ocelots \\ (Leopardus pardalis)] \\ P. Sarti, T.A.R. Paula ${ }^{*}$, G.O. Polli, T. Deco Souza, G.R. Araujo \\ Universidade Federal de Viçosa \\ Campus Universitário \\ Av. PH Rolfs, s/n \\ 36570-000 - Viçosa, MG
}

\begin{abstract}
RESUMO
Estudou-se o espaço intertubular e descreveu-se seu arranjo em jaguatirica adulta (Leopardus pardalis). Para tal, colheram-se fragmentos dos testículos, de cinco jaguatiricas adultas, provenientes de cativeiro, obtidos por biópsia incisional. O compartimento intertubular correspondeu a 19,4\% do parênquima, sendo 3,9\% ocupado por células de Leydig. Estes se apresentaram uninucleados, com o núcleo arredondado e nucléolo único, e com grande quantidade de grânulos pigmentares no citoplasma. O compartimento intertubular apresentou padrão do tipo II, e o tecido conjuntivo foi o componente mais abundante do tecido intertubular. Observou-se pequeno percentual de células de Leydig na espécie estudada, e o número médio por grama de testículo, 33,39 x106 , apresentou-se dentro da amplitude descrita para a maioria dos mamíferos.
\end{abstract}

Palavras-chave: jaguatirica, testículo, espermatogênese, índice Leydigossomático

\begin{abstract}
The aim of this study was to do a quantitative investigation of the intertubular space and describe its arrangement in adult ocelots (Leopardus pardalis). In this experiment we used testicular fragments, obtained through biopsy from five adult ocelots maintained in captivity. The intertubular compartment corresponded to $19.4 \%$ of the testicular parenchyma, and $3.9 \%$ of this compartment was occupied by Leydig cells. The Leydig cells showed to be uninucleate, with rounded nuclei and single nucleoli, with a large amount of pigment granules in their cytoplasm. The intertubular compartment showed a clear pattern of type II and the conjunctive tissue was the most abundant component of the intertubular tissue. Despite the small unit volume of Leydig cells in adult ocelots, the average number per gram of testis (33.39 x106) was within the range described for most mammals.
\end{abstract}

Keywords: ocelot, testis, spermatogenesis, Leydigosomatic index

\section{INTRODUÇÃO}

A caça predatória da jaguatirica (Leopardus pardalis), voltada principalmente para o comércio de pele e a destruição de seu habitat classificam-na atualmente como espécie criticamente em perigo no estado de Minas

Recebido em 7 de junho de 2010

Aceito em 9 de junho de 2011

*Autor para correspondência (corresponding author)

E-mail: tarcizio@ufv.br
Gerais (Machado et al., 1998) e listada no Apêndice I da CITES (Convention..., 2010).

Estudos do processo espermatogênico e da morfologia dos testículos permitiram estabelecer padrões morfofisiológicos da reprodução assistida, ao fornecerem o conhecimento de aspectos reprodutivos de diferentes espécies (Fawcett et al., 1973). A melhor compreensão da 
morfofisiologia reprodutiva de felídeos neotropicais é necessária para aplicar protocolos com a finalidade de favorecer o desempenho reprodutivo de animais em cativeiro, aumentando o número de indivíduos capazes de se reproduzir (Fawcett et al., 1973). Segundo Kenagy e Trombulak (1986), dados biométricos e comportamentais relacionam-se consistentemente e fornecem projeções indicativas importantes da fisiologia reprodutiva.

O presente trabalho teve como objetivo descrever a morfofisiologia do tecido intertubular, em especial da célula de Leydig, de jaguatiricas adultas mantidas em cativeiro.

\section{MATERIAL E MÉTODOS}

Foram utilizadas cinco jaguatiricas machos adultos, de três a nove anos de idade, sendo três oriundas do Centro de Triagem de Animais Silvestres da Universidade Federal de Viçosa, Minas Gerais, conforme autorização do IBAMA, processo número 02015003377/04-19, e duas da Fundação Zoobotânica de Belo Horizonte, conforme convênio de cooperação mútua.

Os animais, contidos pelo uso de dardos anestésicos, foram mantidos sob anestesia geral, com a utilização da associação cloridrato de quetamina $-10 \mathrm{mg} / \mathrm{kg}$ (Dopalen ${ }^{\circledR}$, Vetbrands, SP, Brasil) e cloridrato de xilazina - 1,2mg/kg. Anasedan $^{\circledR}$ (Vetbrands, SP, Brasil). Todo o procedimento foi monitorado, controlando-se temperatura, movimentos respiratórios e batimentos cardíacos, em intervalos de 10 minutos. Após entrarem em plano anestésico, os animais foram pesados, e ambos os testículos mensurados quanto à largura, espessura e comprimento, utilizando-se paquímetro. Por meio da fórmula do volume do elipsóide: $4 / 3 \pi$ $\mathrm{ABC}$, em que: $\mathrm{A}=$ metade da largura, $\mathrm{B}=$ metade da espessura e $\mathrm{C}=$ metade do comprimento, foi calculado o volume testicular em cada animal (Mascarenhas et al., 2006). Como as mensurações foram realizadas percutaneamente, a espessura da pele também foi mensurada e descontada das dimensões testiculares para o cálculo do volume testicular. O volume testicular foi diretamente convertido em gramas, visto que a densidade volumétrica do testículo de mamíferos é igual a 1,046 (Johnson et al., 1981), sendo considerada como 1 por esse autor e por outros que trabalham com espermatogênese (Paula, 1999; Mascarenhas et al., 2006).

Após tricotomia e antissepsia local com iodo polvidine tópico, a pele do escroto foi incisada, com o uso de um bisturi circular de $4 \mathrm{~mm}$ de diâmetro, para se obter um fragmento da região média do testículo esquerdo. Este fragmento foi imediatamente imerso em fixador Karnowsky paraformaldeído 4\% e glutaraldeído 5\% em tampão fosfato $0,1 \mathrm{M} \mathrm{pH} \mathrm{7,4} \mathrm{-} \mathrm{em} \mathrm{temperatura}$ ambiente por, no mínimo, duas horas. Para estudos em microscópio de luz, os fragmentos foram desidratados em série de concentrações crescentes de álcoois $-50^{\circ}, 70^{\circ}, 80^{\circ}, 90^{\circ}, 95^{\circ} \mathrm{e}$ $100^{\circ} \mathrm{GL}$ - e incluídos em resina plástica à base de glicol metacrilato. Foram obtidos tantos cortes histológicos quanto possível, de modo sequencial, utilizando-se micrótomo rotativo dotado de navalha de vidro, com $3 \mu \mathrm{m}$ de espessura. Os cortes foram corados com solução de azul de toluidina-borato de sódio 1\% por um minuto.

Para o cálculo da proporção volumétrica do tecido intertubular, os cortes obtidos foram avaliados em microscópio de luz dotado de ocular integradora com 100 pontos, sob aumento de 640 vezes. Em cada animal foram contabilizados, em 10 campos distribuídos aleatoriamente, pontos sobre túbulos seminíferos, núcleos de célula de Leydig, citoplasma de células de Leydig, tecido conjuntivo e vasos sanguíneos. Inferindo-se por estas proporções o volume total do parênquima testicular, foi obtido o volume de cada componente avaliado. Foi calculada, ainda, a relação núcleo:citoplasmática da célula de Leydig, dividindo-se os pontos computados em núcleos por aqueles em citoplasma das células de Leydig.

Foi realizada a mensuração do diâmetro de 10 núcleos de células de Leydig por animal, com o auxílio de microscópio de luz sob aumento de 1000 vezes, com ocular micrométrica acoplada. A partir deste, calculou-se o volume nuclear por meio da fórmula do volume da uma esfera $4 / 3 \pi r^{3}-$, em que $r$ (raio) corresponde à metade do diâmetro nuclear. Pela razão núcleo/citoplasma, foram calculados o volume citoplasmático e o volume de uma célula de Leydig. Inferindo-se o volume de uma célula de Leydig pelo volume total de células de Leydig por testículo, obteve-se 
o número total destas células por testículo, e dividindo-se pela massa de testículo, obteve-se o seu número por grama de testículo. A partir do volume total das células de Leydig e do peso corporal, foi possível calcular o índice leydigossomático, o qual se refere ao percentual de massa corporal alocado em células de Leydig.

Com esse procedimento, obtiveram-se: média, desvio-padrão e coeficiente de variação. Em alguns casos, foi aplicado o teste de coeficiente de correlação e calculou-se o intervalo de confiança a 5\%, segundo a função estatística do programa Excel/Windows XP.

\section{RESULTADOS}

A célula de Leydig da jaguatirica apresentou-se uninucleada e com o núcleo arredondado contendo uma fina camada de heterocromatina ao longo do envoltório nuclear e, na maioria das vezes, com um único nucléolo. Observou-se também grande quantidade de lipofucsina, ou pigmento lipocromo.

O tecido intertubular representou, em média, 19,4\% do parênquima testicular, enquanto as células de Leydig representaram 3,9\% deste (Tab. 1). A maior parte do tecido intertubular está constituída de tecido conjuntivo frouxo, com presença, ainda, de células de Leydig e de vasos sanguíneos e linfáticos, compondo, assim, respectivamente, 13,3; 3,9 e 2,2\% do parênquima testicular.

O volume médio da célula de Leydig foi de $913,39 \mu \mathrm{m}^{3}$, o diâmetro, $8,48 \mu \mathrm{m}$, e o volume nuclear médio, 320,25 $\mu^{3}$ (Tab. 2). Nesta tabela também estão os resultados de outras medidas das células de Leydig e o índice leydigossomático.

Tabela 1. Volume e proporção volumétrica do tecido intertubular das células de Leydig, do tecido conjuntivo e dos vasos sanguíneos e linfáticos de jaguatirica adulta mantida em cativeiro

\begin{tabular}{lc}
\hline \multicolumn{1}{c}{ Característica } & $\begin{array}{c}\text { Média } \pm \text { desvio-padrão } \\
\text { (coeficiente de variação) }\end{array}$ \\
\hline Volume total de tecido intertubular (mL) & $2,58 \pm 0,79$ \\
Proporção volumétrica de tecido intertubular (\%) & $(30,77)$ \\
Volume total de células de Leydig (mL) & $19,39 \pm 4,04$ \\
& $(20,86)$ \\
Proporção volumétrica de células de Leydig (\%) & $0,51 \pm 0,19$ \\
& $(36,21)$ \\
Volume total de tecido conjuntivo (mL) & $3,90 \pm 1,33$ \\
& $(34,16)$ \\
Proporção volumétrica de tecido conjuntivo (\%) & $1,78 \pm 0,78$ \\
Volume total de vasos sanguíneos e linfáticos (mL) & $(43,88)$ \\
Proporção volumétrica de vasos sanguíneos e linfáticos (\%) & $(33,16)$ \\
\hline
\end{tabular}

\section{DISCUSSÃO}

Fawcett et al. (1973) descreveram três modelos para o arranjo dos componentes do espaço intertubular nas diferentes espécies, indicando grande variação em relação à quantidade de células de Leydig e à disposição de vasos/espaços linfáticos. Apesar do pouco conhecimento a respeito das implicações fisiológicas dessas variações, Fawcett et al. (1973) e Russell (1996) especularam que elas estejam, provavelmente, relacionadas à habilidade dos vasos linfáticos em mover para fora dos testículos material vascularmente secretado e em manter concentrações adequadas de andrógenos nos testículos e nos vasos sanguíneos. 
Tabela 2. Volume médio de uma célula de Leydig, volume e diâmetro nucleares, relação núcleo:citoplasmática de células de Leydig, número total e por grama de testículo de células de Leydig e índice leydigossomático de jaguatirica adulta mantida em cativeiro

\begin{tabular}{lc}
\multicolumn{1}{c}{ Característica } & $\begin{array}{c}\text { Média } \pm \text { desvio-padrão } \\
\text { (coeficiente de variação) }\end{array}$ \\
\hline Diâmetro do núcleo $(\mu \mathrm{m})$ & $8,48 \pm 0,27$ \\
& $(3,23)$ \\
Volume de uma célula de Leydig $\left(\mu \mathrm{m}^{3}\right)$ & $913,39 \pm 90,2$ \\
& $(9,87)$ \\
Volume nuclear $\left(\mu \mathrm{m}^{3}\right)$ & $320,25 \pm 31,80$ \\
& $(9,93)$ \\
Relação núcleo:citoplasma $(\%)$ & $35,11 \pm 2,07$ \\
& $(5,90)$ \\
Número de células totais & $569,63 \times 10^{6} \pm 239,55 \times 10^{6}$ \\
Número de células/g testículo & $(42,05)$ \\
& $33,39 \times 10^{6} \pm 13,53 \times 10^{6}$ \\
Índice leydigossomático $(\%)$ & $(40,57)$ \\
\end{tabular}

À semelhança do observado para outros felinos, como o gato doméstico (Godinho, 1999), a onça parda (Guião Leite e Paula, 2003), a onça pintada (Azevedo et al., 2008) e o leão africano (Barros, 2005), a jaguatirica apresenta o padrão do tipo II na classificação de Fawcett et al. (1973). Na jaguatirica, o tecido conjuntivo foi o componente mais abundante do tecido intertubular dentre felinos já estudados, sendo esta relação semelhante somente ao observado na onça parda (8,3\%; Guião Leite e Paula, 2003). Já em outros felinos, a célula de Leydig é o principal componente do espaço intertubular, ocupando 73\% do parênquima testicular no gato-do-matopequeno (Balarini, 2008), 18\% no leão africano (Barros et al., 2004), 13\% na onça pintada (Azevedo et al., 2008) e 6\% no gato doméstico (Godinho, 1999).

Semelhante ao verificado no citoplasma da célula de Leydig da onça pintada (Azevedo et al. 2008), observou-se grande quantidade do pigmento de lipofucsina nas células de Leydig da jaguatirica adulta. Esse pigmento é relatado também em células de Leydig de cobaio, tatu e humanos (Russell, 1996). O pigmento de lipofucsina, ou pigmento lipocromo, é considerado uma forma semidegradada de lipídio envolvido em membrana, segundo esses autores.

O diâmetro $(8,48 \mu \mathrm{m})$ e o volume nuclear médio $\left(320,25 \mu \mathrm{m}^{3}\right)$ das células de Leydig da jaguatirica foram maiores do que os valores observados para o gato-do-mato-pequeno $\left(7,0 \mu \mathrm{m}\right.$ e $180,05 \mu \mathrm{m}^{3}$; Balarini, 2008), a onça pintada $(7,7 \mu \mathrm{m}$ e $240 \mu$ $\mathrm{m}^{3}$; Azevedo et al., 2008) e o gato doméstico (7,9 $\mu \mathrm{m}$ e $261 \mu \mathrm{m}^{3}$; Godinho, 1999). Na maioria dos animais já estudados, o núcleo da célula de Leydig corresponde de 10 a $19 \%$ do volume total da célula (França e Russell, 1998). Na jaguatirica adulta, essa característica $(35,1 \%)$ foi muito acima do observado no gato-do-mato-pequeno (23,9\%), na onça pintada (10\%) e no leão africano (7,4\%), citados pelos mesmos autores.

O volume médio individual das células de Leydig $\left(913,39 \mu \mathrm{m}^{3}\right)$ foi mais baixo que o observado em outros felinos já citados, como o leão africano $\left(1894,6 \mu^{3}\right)$, a onça pintada (2386 $\left.\mu \mathrm{m}^{3}\right)$ e o gato doméstico $\left(2044 \mu \mathrm{m}^{3}\right)$, e abaixo, ainda, dos valores relatados para roedores de laboratório e o homem (Russell, 1996), porém relativamente próximo ao do gato-do-matopequeno $\left(765,61 \mu \mathrm{m}^{3}\right)$. Ewing et al. (1979) observaram que a capacidade de produção de testosterona da célula de Leydig está correlacionada com a quantidade de retículo endoplasmático liso. Costa et al. (2006) observaram que, em capivara, há correlação positiva entre o percentual das células de Leydig e a produção de testosterona, porém esta produção hormonal não pode ser correlacionada com a população total dessas células. Estes resultados confirmam que a produção de esteróides para atender à demanda de cada 
espécie está mais relacionada à capacidade individual da célula de Leydig em secretar tais hormônios do que com a proporção volumétrica e a população delas no testículo (Ewing et al., 1979).

Apesar do pequeno percentual das células de Leydig, o número médio de células por grama de testículo, 33,39 $\times 10^{6}$, apresentou-se dentro da amplitude descrita para a maioria dos mamíferos, entre 20 e 40 milhões (Russell, 1996; França e Russell, 1998), semelhante ao observado na onça pintada $\left(39,4 \times 10^{6}\right)$, porém mais baixo que o descrito para o gato-do-mato-pequeno $\left(114 \times 10^{6}\right)$. Todos esses resultados são um reflexo da elevada variação interespecífica na quantidade de células de Leydig por grama de testículo, incluindo a jaguatirica, e também pela variação intraespecífica, demonstrada pelo elevado coeficiente de variação encontrado. Inúmeros fatores podem afetar a quantidade de células de Leydig necessária por animal, dentre os quais podem ser destacados: a quantidade de $\mathrm{LH}$ disponível para estimular a célula, o número de receptores para LH por célula, a capacidade individual de produção de testosterona, a velocidade pela qual a testosterona deixa o testículo, o volume de sangue e, até mesmo, a taxa metabolizada da testosterona (Russell, 1996; Russell et al., 1994). Tais necessidades individuais podem explicar a elevada variação inter e intraespecífica do número de células de Leydig.

O índice leydigossomático corresponde à massa corpórea alocada em células de Leydig. Em jaguatirica, as células de Leydig correspondem a $0,0036 \%$ da massa corporal, semelhante ao observado para a onça pintada $(0,0036 \%)$ e para o leão africano (0,0023\%), porém menor que o descrito para o gato-do-mato-pequeno $(0,005 \%)$. Apesar de o total de células de Leydig por grama de testículo do gato-do-mato-pequeno ser aproximadamente três vezes maior que o da jaguatirica, o índice leydigossomático foi apenas 1,38 vezes maior, indicando que, em ralação à massa corpórea, a quantidade destas células não é tão discrepante quanto à observada por grama de testículo. Dessa forma, por considerar a massa corpórea e não somente a testicular, que também varia entre as espécies, pode-se inferir que o índice leydigossomático é um parâmetro mais apropriado para comparação entre espécies.

\section{CONCLUSÕES}

Embora as jaguatiricas possuam células de Leydig de pequeno volume, o número por grama de testículo é semelhante ao dos demais felinos estudados. Esta espécie apresenta o padrão tipo II na classificação de Fawcett et al. (1973) para o arranjo dos componentes do espaço intertubular.

\section{REFERÊNCIAS BIBLIOGRÁFICAS}

AZEVEDO, M.H.F.; PAULA, T.A.R.; BALARINI, M.K. et al. Organization and quantification of the elements in the intertubular space in the adult jaguar testis (Panthera onca, LINNAEUS, 1758). Micron, v.39, p.1166-1176, 2008.

BALARINI, M.K. Análise morfofuncional do testículo e do processo espermatogênico do gatodo-mato-pequeno (Leopardus tigrinus, Schreber, 1775) adulto. 2008. 71f. Dissertação (Mestrado) - Universidade Federal de Viçosa, Viçosa, MG.

BARROS, J.B.G. Análise morfofuncional do testículo e espermatogênese de leões africanos (Panthera leo, Linnaeus, 1758) adultos. 2005. 77f. Dissertação (Mestrado) - Universidade Federal de Viçosa, Viçosa, MG.

BARROS, J.B.G.; PAULA, T.A.R.; AZEVEDO, M.H.F. et al. Population of the seminiferous epithelium, intrinsic yield of spermatogenesis and Sertoli cells index in adult lions (Panthera leo) raised in captivity. In: INTERNATIONAL SYMPOSIUM ON CANINE AND FELINE REPRODUCTION, 5., 2004, Embu das Artes, SP. Proceedings... Embu dasArtes: Book, 2004.

CONVENTION ON INTERNATIONAL TRADE IN ENDANGERED SPECIES OF WILD FAUNA AND FLORA. CITES Species Databases. 2010. Disponível em: <http://www.cites.org/eng/resources/species.html >. Acessado em: 10 jan. 2010.

COSTA, D.S.; PAULA, T.A.R.; HENRIQUES, L.S.V. et al. Concentração de testosterona, volume da glândula nasal e morfometria das células de leydig em capivaras (Hydrochoerus hydrochaeris). Rev. Univ. Rural, Serie Cienc. Vida, v.26, supl., p.19-20, 2006. 
EWING, L.L.; ZIRKIN, B.B.; COCHRAN, R.C. et al. Testosterone secretion by rat, rabbit, guinea pig, dog, and hamster testes perfused in vitro: correlation with Leydig cell mass. Endocrinology, v.105, p.1135-1142, 1979.

FAWCETT, D.W.; NEAVES, W.B.; FLORES, M.N. Comparative observations on intertublar lymphatic and the organization of the interstitial tissue of the mammalian testis. Biol. Reprod., v.9, p.500-532, 1973.

FRANÇA, L.R.; RUSSELL, L.D. The testis of domestic animals. In: REGADERA, J.; MARTINEZ-GARCIA (Eds.). Male reproduction: a multidisciplinary overview. Madrid: Churchill Livingstone, 1998. p. 197219.

GUIÃO LEITE, F.L.; PAULA, T.A.R. Intrisec yield of spermatogenesis, Sertoli cell index and daily sperm production in cougar (Puma concolor), Rev. Bras. Reprod. Anim., v.27, p.121, 2003.

GODINHO, C.L. Análise histométrica do testículo e duração da espermatogênese em gatos (felis domestica) sexualmente maduros. 1999. 80f. Dissertação (Mestrado em Medicina Veterinária) - Universidade Federal de Viçosa, Viçosa, MG.

JOHNSON, L.; PETTY, C.S.; NEVES, W.B. A new approach to qualification of spermatogenesis and its application to germinal cell attrition during human spermatogenesis. Biol. Reprod., v.25, p.217-226, 1981.
KENAGY, G.J.; TROMBULAK, S.C. Size and function of mammalian testes in relation to body size. J. Mamm., v.67, p.1-22, 1986.

MACHADO, A.B.M.; FONSECA, G.A.B.; MACHADO, R.B. et al. Livro brasileiro das espécies ameaçadas de extinção da fauna de Minas Gerais. Belo Horizonte: Fundação Biodiversitas, 1998. 608 p.

MASCARENHAS, R.M.; PAULA, T.A.R.; MATTA, S.L.P. et al. Morfometria macro e microscópica e índices somáticos dos componentes testículares de cães sem raça definida, da puberdade à senilidade. Rev. Ceres, v. 53, p.113-119, 2006.

PAULA, T.A.R. Avaliação histológica e funcional do testículo de capivaras adultas (Hydrochoerus hydrochaeris). 1999. 84f. Tese (Doutorado) - Universidade Federal de Minas Gerais, Belo Horizonte, MG.

RUSSELL, L.D. Mammalian Leydig cell structure. In: PAYNE, A.H., HARDY, M.P., RUSSELL, L.D. (Eds). The Leydig cell. Vienna: Cache River, 1996. p.218-222.

RUSSELL, L.D.; CHANDRASHEKAR, V.; BARTKE, A. et al. The hamsters sertoli cell in early testicular regression and early recrudescence: a stereological and endocrine study. Int. J. Androl., v.17, p.93-106, 1994. 